\title{
TERRITORIALIDADES E A PRODUÇÃO DA MORADIA DOS BOLIVIANOS NA CIDADE DE CORUMBÁ-MS, BRASIL ${ }^{1}$
}

\author{
TERRITORIALITIES AND THE HOUSING PRODUCTION OF \\ BOLIVIANS IN THE CITY OF CORUMBÁ-MS, BRAZIL
}

\section{TERRITORIALIDADES Y PRODUCCIÓN DE VIVIENDA DE LOS BOLIVIANOS EN LA CIUDAD DE CORUMBÁ-MS, BRASIL}

\author{
Ramona Trindade Ramos Dias \\ Mestre em Estudos Fronteiriços, CPAN/UFMS \\ E-mail: ramona.trindade@ hotmail.com \\ Edgar Aparecido da Costa \\ Professor do Mestrado em Estudos Fronteiriços \\ Universidade Federal do Mato Grosso do Sul, Campus do Pantanal \\ E-mail: edgarac10@gmail.com
}

\begin{abstract}
Resumo
A cidade de Corumbá-MS (Brasil) é vizinha do distrito de Arroyo Concepción e do município de Puerto Quijarro-SC (Bolívia), cuja proximidade e construção histórica fronteiriça a coloca num contexto de possibilidades para o processo migratório de povos bolivianos. O objetivo deste artigo é conhecer a motivação migratória dos bolivianos que ora residem em Corumbá-MS e identificar suas territorialidades numa nova terra, a partir da fixação de suas moradias. Metodologicamente foi adotada pesquisa bibliográfica e trabalho de campo utilizando entrevistas e conversas informais com os migrantes e com representantes dos órgãos ligados ao setor na cidade de Corumbá-MS. Também se utilizou a técnica da observação das paisagens urbanas fronteiriça. Foi possível compreender que a saída dos bolivianos de seus locais de origem esteve ligada à busca de trabalho para melhorar a condição de vida, utilizando as informações contidas nas redes sociais e se adaptando rapidamente às condições do novo território.
\end{abstract}

Palavras-chave: Fronteira, Corumbá-MS, migração, territorialidade.

\section{Abstract}

The city of Corumbá-MS (Brazil), as well as Puerto Quijarro-SC and the district of Arroyo Concepción (Bolivia), are neighbors, whose proximity and borderline historical construction create a context of possibilities to the Bolivian migratory process. This article aims to know the migratory motivation of Bolivians who live in Corumbá-MS, and identify its territorialities in a new land, in regards of fixed housing. Methodologically, it was adopted a bibliographic research and field work using interviews and informal talking with the migrants and with public organization

\footnotetext{
${ }^{1}$ Pesquisa realizada com apoio financeiro da FUNDECT- Fundação de Apoio ao Desenvolvimento do Ensino, Ciência e Tecnologia do Estado de Mato Grosso do Sul.
}

Ateliê Geográfico Goiânia-GO v. $5, n .3$ dez/2011 p.127-149 Página


representatives of Corumbá-MS. The technique of frontier urban landscape observation was also used in this study. It was possible to understand that the Bolivian departure from their places of origin was connected to the search of work in order to achieve better living conditions, using the information available in social network and quickly adapting to the new territory conditions.

Key-words: Border, Corumbá-MS, migration, territoriality.

\section{Resumen}

La ciudad de Corumbá-MS (Brasil) es vecina de lo distrito de Arroyo Concepción y del municipio de Puerto Quijarro-SC (Bolivia), cuya proximidad y construcción histórica fronteriza la pone en un contexto de posibilidades a un proceso de migración de personas bolivianas. El objetivo de este artículo es conocer la motivación migratoria de los bolivianos que ahora residen en Corumbá-MS y identificar sus territorialidades en una nueva tierra a partir del establecimiento de sus viviendas. Metodológicamente fue adoptada un estudio bibliográfico y trabajos de campo utilizando entrevistas y conversaciones informales con los inmigrantes y representantes de los órganos vinculados al sector en Corumbá-MS. También se utilizó la técnica de observación de los paisajes urbanos fronterizos. Se puede entender que la salida de los bolivianos de sus localidades de origen está vinculada con la procura de trabajo para mejorar sus condiciones de vida, utilizando las informaciones contenidas en las redes sociales y adaptándose rápidamente a las condiciones del nuevo territorio.

Palabras-clave: Frontera, Corumbá-MS, migración, territorialidad.

\section{Introdução}

Estudar uma região fronteiriça implica em reconhecer as singularidades do povo residente e na compreensão das subjetividades envolvidas ou desenvolvidas pelas tramas territoriais dos diversos atores/agentes da produção desse espaço. Este artigo é uma parte modificada de nossa dissertação de mestrado no Programa de Pós-Graduação em Estudos Fronteiriços da Universidade Federal de Mato Grosso do Sul, no Campus do Pantanal, cuja pesquisa foi aprovada pelo Comitê de Ética daquela Instituição de Ensino Superior.

O objetivo deste artigo foi, primeiramente, entender o que levou os migrantes bolivianos abandonarem sua terra natal para virem morar em Corumbá e, concomitantemente, analisar as territorialidades desenvolvidas por esse grupo populacional. Trata-se da exposição de alguns resultados de uma pesquisa qualitativa, apoiada nas entrevistas gravadas a partir de um roteiro pouco rígido, de modo a permitir a intromissão de novos elementos próprios da dinâmica imposta das conversas estabelecidas. Apoiou-se ainda em material bibliográfico e na observação da paisagem.

Ateliê Geográfico Goiânia-GO v. 5,n. 3 dez/2011 p.127-149 Página


O trabalho de campo contemplou uma amostra da população de bolivianos residentes em Corumbá-MS, cuja localização foi indicada em estudo anterior realizado por Baeninger e Souchaud (2007). Após a identificação do primeiro migrante para entrevista foi utilizada a técnica da "bola de neve", ou seja, um entrevistado indicava o próximo e assim sucessivamente. Optamos por realizar 25 entrevistas com pessoas que vieram de diversas localidades e já estavam estabelecidas na cidade de Corumbá-MS, num período médio de aproximadamente 40 anos. Entendemos que esse grupo, pelo fato de estar entre os primeiros a se estabelecer nesta localidade, teria maior capacidade de detalhamento de suas ações, pois o tempo de estadia oferece maior segurança para expor suas territorialidades sem maiores complicações. Procuramos indagar sobre o estabelecimento de suas moradias, tanto para a aquisição ou construção do imóvel, como também pela escolha do lugar, tendo como objetivo a definição de suas territorialidades.

$\mathrm{O}$ artigo foi organizado em quatro etapas complementares. Primeiramente, se buscou entender conceitualmente migração e territorialidade, especulando sobre ambas a partir da experiência empírica. Em seguida se descreveu as causas das migrações e como os bolivianos foram para Corumbá-MS, no Brasil. Posteriormente, como se constituíram as redes sociais estabelecidas durante o processo de migração e, por fim, se realizou a descrição e discussão das características das moradias dos bolivianos na cidade de Corumbá-MS.

\section{Migração e territorialidade}

Quando as pessoas desenvolvem estratégias de sobrevivência, de melhoria da qualidade de vida, ou simplesmente de deslocamentos, pode se denominar essas ações de territorialidades. Essa ação ocorre no espaço apropriado enquanto território, não fora dele, sempre através ou pelo território. Raffestin (1993, p.143) esclarece a diferença temporal entre espaço e território ao afirmar que:

É necessário compreender bem que o espaço é anterior ao território. O território se forma a partir do espaço, é o resultado de uma ação conduzida por um ator sintagmático (ator que realiza um programa) em qualquer nível. Ao se apropriar de um espaço, concreta ou abstratamente [...] o ator territorializa o espaço. 


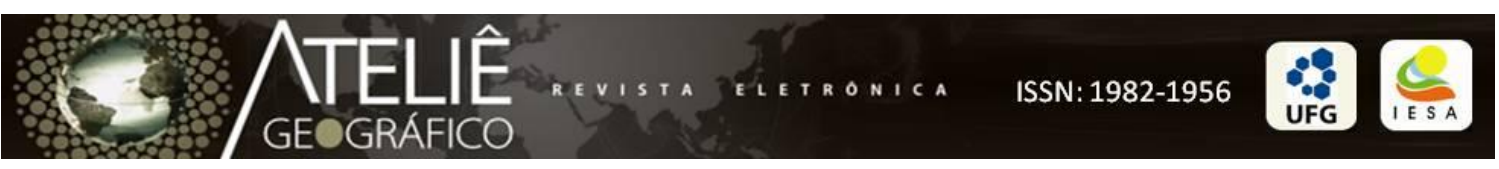

Dessa concepção se pode inferir que territorialidade é toda a ação do ser humano sobre o território, ou seja, toda relação social, política, econômica, cultural que se concretiza num dado espaço apropriado pelas relações de poder, seja governamental, individual ou de uma coletividade. No entendimento de Saquet (2007, p.81):

O território é produzido espaço-temporalmente pelas relações de poder engendradas por um determinado grupo social. Dessa forma, pode ser temporário ou permanente e se efetiva em diferentes escalas, portanto, não apenas naquela convencionalmente conhecida como o território.

Dessa forma, o território é o espaço ocupado pelo ser humano, onde realiza suas atividades, sendo que a territorialidade é determinada por suas relações mediatizadas pelo ambiente. A forma de manifestação da territorialidade não é, necessariamente, permanente, haja vista que o ser humano é um ser social que se desenvolve e se transforma ao longo dos tempos. Esse desenvolvimento ou transformações de comportamento influencia na sua relação com a sociedade, produzindo então novas territorialidades. Daí seu entendimento como uma produção espaço-temporal, já que ocorre em determinado espaço-tempo e varia de acordo as transformações sociais.

O ser humano quando se move de um lugar para outro, para outras terras, o faz por não sentir a satisfação de suas necessidades ou desejos. É muitas vezes impulsionado a buscar novos horizontes, quer seja pelo imperativo da necessidade de sobrevivência ou realização de projetos mais elaborados. Nessa acepção, a migração pode ser percebida como uma aspiração do ser humano pelo seu próprio desenvolvimento, em busca de melhores condições e qualidade de vida, podendo ser motivada por diferentes fatores, como: políticos, religiosos, culturais e econômicos. Este último é, provavelmente, o que mais se destaca.

O aprofundamento do processo de globalização certamente contribuiu para a intensificação dos fluxos de pessoas interna e externamente à escala nacional. Entretanto, partindo do pressuposto de que o ser humano é um ser social, esses fatores não podem ser analisados parcialmente, uma vez que a vida humana é complexa e sua explicação se dá pela totalidade e não pelas particularidades. Os fluxos populacionais são explicados pelas combinações de inúmeros processos, mas não se pode generalizar. Cada grupo tem suas particularidades e motivações que não se reproduz, da mesma forma, em nenhum outro grupo. 
O processo migratório envolve mudanças que vai muito além de fatores econômicos, pois a presença de um migrante pode produzir profícua interação de culturas e costumes. O contato com o novo não só induz a mudanças no estilo de vida do migrante, para se adequar ao território e suas normas, como também pode seduzir a sociedade local para as novidades trazidas, havendo, portanto, influências recíprocas. Se por um lado a migração provoca a ampliação das necessidades de oferta de moradia e suas consequentes variantes (energia, saneamento básico, escolas, creches, atendimento de saúde etc.), por outro, possibilita trocas de experiências, costumes e culturas diferentes que produzem um hibridismo salutar nas formas de relacionamento com ambiente.

Assim, é incontestável a participação e a influência que o migrante produz no lugar que o recebe, tanto nos aspectos funcionais quanto simbólicos. No primeiro envolve o trabalho, pela necessidade de subsistência no lugar e pela contribuição no campo profissional ou intelectual. No aspecto simbólico, o novo implica na (re)criação de significados crescentemente incorporados do cotidiano onde as experiências de vida se manifestam, se trocam e se renovam.

Esse é o caráter da territorialidade, como um processo de construção, desconstrução e reconstrução dos territórios. Nas palavras de Costa (2009, p.63), as especificidades do território “[...] são produzidas historicamente pela capacidade e disponibilidade dos recursos e tecnologia, bem como de acesso a elas pelos diversos segmentos sociais". A territorialidade pressupõe, dessa forma, um movimento descontínuo, uma vez que cada segmento ou sociedade terá distintas formas de se relacionar com o território, em função de contextos históricos, culturais, econômicos nos quais estão inseridos. Ao mesmo tempo em que se constrói um novo panorama, ainda se vivencia comportamentos passados.

A migração carrega, em seu bojo, o processo T-D-R (territorializaçãodesterritorialização-reterritorialização), introduzido por Raffestin (1993) e sistematicamente discutido, no Brasil, por Haesbaert (2008, 2004, 2003 e 2002). Na medida em que abandona sua terra de origem o ser humano se desterritorializa para se territorializar numa nova localidade. Isso porque, na visão de Deleuze e Guattari, (1997, p.224) “A desterritorialização [...] é inseparável de reterritorializações correlativas”. 


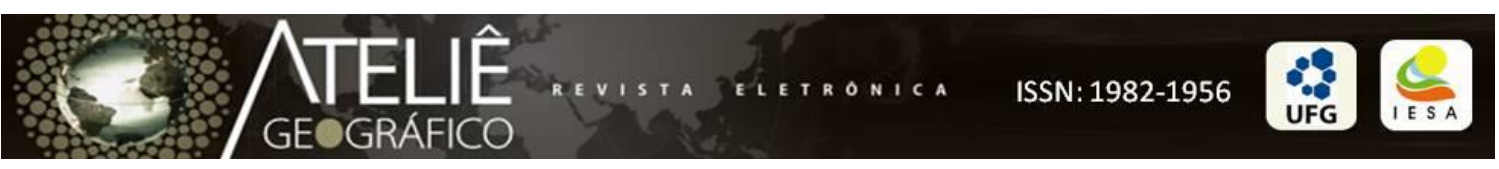

Para Golgher (2004), “[...] o migrante é o indivíduo que morava em um determinado município e atravessou a fronteira deste município indo morar em outro distinto". Partindo desse pressuposto e da relação do ser humano com o meio, com o território onde exerce seu caráter relacional, modificando-o de acordo com diferentes contextos, é possível afirmar que a migração é um importante fator de produção de novas territorialidades.

\section{Os migrantes bolivianos: no caminho de Corumbá-MS, no Brasil}

A fim de tentar entender como os bolivianos se deslocaram dos seus locais de origem até Corumbá-MS, foram realizadas 25 entrevistas com pessoas que residem há muito tempo nessa cidade, variando entre 18 e 50 anos. Notou-se que a maioria não fixou residência em Puerto Quijarro (Bolívia), vizinha à linha divisória internacional. Aquele local foi utilizado apenas como um ponto de passagem e, também, como uma espécie de elo com o país de origem, uma vez que raramente voltaram para o local de saída. Contudo, os entrevistados afirmaram realizar visitas periódicas a parentes e conhecidos nas cidades de Puerto Quijarro e Puerto Suarez (Bolívia), aonde vão também para participar dos pleitos eleitorais, para aquisições de mercadorias e outras atividades - denunciando a dupla cidadania.

Esses migrantes possuem diversas origens, acenando para migrações de pequenos grupos. Nas entrevistas se constatou as diversas localidades da Bolívia (Figura 1), como: Cochabamba, Concepción, El Salado, Estação Motacucito, La Paz, Roboré, Potosí, Puerto Suarez, São José de Chiquitos, São Miguel, San Ignacio de Velasco, Trinidad entre outras localidades.

Sobre a decisão em mudar de país foi apontada, principalmente, a possibilidade de exercer um trabalho com melhor remuneração para, com isso, produzirem uma melhoria da qualidade de vida. Também foi mencionada a perspectiva de oferecer uma formação escolar aos filhos em idade estudantil, ressaltando a diferença de qualidade no setor educacional entre os países.

Conforme os depoimentos obtidos, foi possível perceber que a maioria cursou apenas o ensino fundamental em suas séries iniciais. Em raríssimas situações foi citada a conclusão do ensino médio e, mesmo do ensino fundamental. Dentre os entrevistados,

Ateliê Geográfico Goiânia-GO v. 5, n. 3 dez/2011 p.127-149 Página


apenas um informou ter migrado para Corumbá após a conclusão do ensino superior, porém sua perspectiva não se diferenciou dos demais - via na cidade a realização de suas atividades profissionais e o sonho de uma vida melhor.

Em Corumbá, os filhos desses migrantes puderam desfrutar de melhores condições para a sua formação educacional apresentando grau de escolaridade superior à dos pais, com ensino médio concluído e ensino superior, em menor escala. Nos casos em que encontramos filhos ainda crianças, todas estavam matriculadas na rede de ensino municipal. Assim, se pode afirmar que esses migrantes obtiveram êxito, ao menos parcial, em seus anseios, já que de acordo com as suas falas, a educação escolar é uma ferramenta que os coloca em melhores condições de conhecimento para desenvolverem as atividades profissionais.

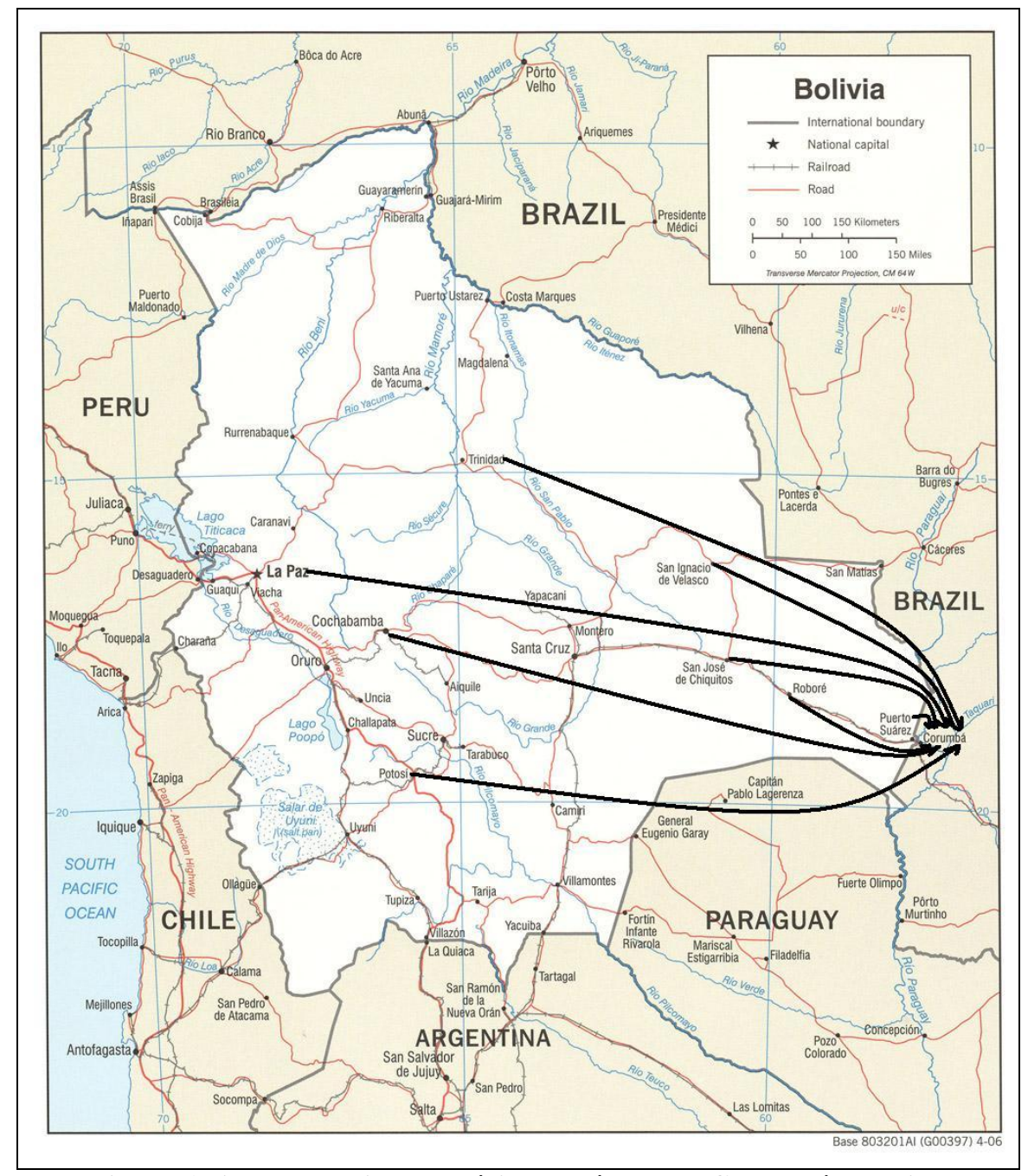

Figura 1. Alguns locais da Bolívia de saída para Corumbá, Brasil. Fonte: Adaptado pelos autores a partir de imagem disponível em: http://www.vmapas.com, acesso em $20 \operatorname{dez} 2010$. 
Vale destacar que todos os entrevistados mencionaram que a baixa qualidade de vida em seus locais de origem foi uma das principais motivações migratórias. Descreveram ambientes de muita pobreza e dificuldades, inclusive na alimentação que se baseava principalmente nos alimentos oriundos da lavoura e da criação de pequenos animais. Reportamos uma narrativa peculiar de um dos entrevistados, que oferece uma idéia sobre essa condição: "Comemos até bicho... bicho... sabe como é esse bicho? Meu pai cortava o palmito e fazia um buraco, depois de uns quinze dias aparecia esse bicho, tipo coró... branco, gordo, gostoso... meu pai ia com minha mãe, pegava no latão e tostava aquilo...". Noutro ponto de sua fala, esse mesmo senhor faz referência ao consumo de formigas - também tostadas, da mesma forma que o outro inseto - que comiam com mandioca.

Logo, a condição de pobreza foi um grande motivador de expulsão da terra natal. Diante desta perspectiva se procurou, então, conhecer como ocorreu essa atração por Corumbá. Um dos principais facilitadores foi a implementação da estrada de ferro ligando Corumbá a Santa Cruz de La Sierra, cujos trabalhos foram conduzidos por um grupo denominado de Comissão Mista, exatamente por envolver o trabalho de brasileiros e bolivianos. Muitos vieram para o trabalho na ferrovia, assim como a utilizaram como a principal via de transporte para viagens de comércio - atividade profissional preponderante entre eles. Referiram-se ao exercício da "pilotagem", já que na verdade serviam de transportadores de mercadorias para proprietários de comércio. Esse fato, aliado ao costume de realizarem passeios na cidade de Corumbá foram os principais fatores que permitiram o conhecimento deste local, despertando o sonho de transformarem suas vidas para melhor. Posteriormente, os demais familiares chegaram sob a influência e cooperação daqueles que primeiramente aportaram e se estabeleceram em Corumbá - denunciando a existência de redes de solidariedade.

A atração exercida por Corumbá está relacionada muito mais com o fato de ser uma cidade fronteiriça com oportunidades de emprego do que propriamente com seu passado glorioso. A cidade já foi, até o primeiro quartel do século $\mathrm{XX}$, o terceiro maior porto da América do Sul. A possibilidade de convivência fronteiriça permitiu a principal

\footnotetext{
${ }^{2}$ Alguns denominaram as pessoas que desenvolviam essa atividade como "mulas".
}

Ateliê Geográfico Goiânia-GO v. 5,n. 3 dez/2011 p.127-149 Página




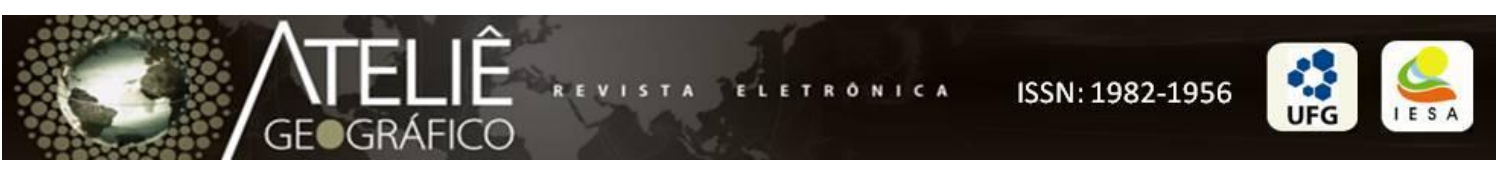

estratégia utilizada pelos bolivianos que foi a da permanência dissimulada entre os moradores da cidade.

A fronteira está sendo, aqui, compreendida em conformidade com a proposição de Nogueira (2007, p.28): um "[...] lugar de referência identitária, como um dado da cultura[...]. Dessa forma, igualmente, foi considerado importante focar análise sobre os conceitos: "[...] existir, identificar, significar, simbolizar, compreender, experienciar, perceber, habitar, ser, viver, etc." A fronteira é vista como área ocupada por pessoas de dois territórios distintos, interpenetrados por diversas formas de relacionamento. É uma localidade híbrida, antes de tudo, a ponto de Castrogiovanni e Gastal (2006) denominarem-na de terceiro espaço.

\section{As redes sociais e a migração dos bolivianos para Corumbá}

A maioria dos migrantes entrevistados veio ainda muito jovem para o Brasil, sem ter realizado atividade profissional que mantivesse a sua subsistência na localidade. O impulso de uma nova vida se originou das dificuldades familiares vividas, conforme apontado anteriormente. Entre os que afirmaram já terem trabalhado antes, se observou que sua experiência não foi valiosa para o novo local de estabelecimento. Nos locais de origem, trabalhavam principalmente na agricultura e em Corumbá passaram a se dedicar a outras atividades, como trabalho nas fábricas, hotéis, residências. Essas características dos migrantes bolivianos vêm sendo alteradas. Nas conversas com os coordenadores da Pastoral do Imigrante e do Centro Boliviano-Brasileiro ficaram evidentes que os novos grupos bolivianos que tem chegado a Corumbá, especialmente a partir dos anos 1990, são diferenciados do ponto de vista da qualificação. Muitos já estão chegando com mais habilidades e capacidades competitivas para o mercado de trabalho.

Em relação à existência de uma rede estruturada ou formal que efetivamente estivesse envolvida no processo migratório para o Brasil, os entrevistados indicaram que o interesse pela mudança para esta cidade ocorreu de forma espontânea e individual. O processo migratório se deu de forma muito particular, sem a interferência e colaboração de outras pessoas ou instituições. Contudo, como se pôde perceber, existiam, sim, as redes, porém com poucos elos. As pessoas que de alguma forma apoiaram na vinda dos migrantes são elementos da trama territorial, que, em acordo com Raffestin (1993,

Ateliê Geográfico Goiânia-GO v. 5, n. 3 dez/2011 p.127-149 Página


p.156): "agem e, em conseqüência, procuram manter relações, assegurar funções, se influenciar, se controlar, se interditar, se permitir, se distanciar ou se aproximar e, assim, criar redes entre elas".

Para Raffestin (1993, p.156):

Uma rede é um sistema de linhas que desenham tramas. Uma rede pode ser abstrata ou concreta, invisível ou visível. A idéia básica é considerar a rede como algo que assegura comunicação, mas, por natureza, a rede que desenha os limites e as fronteiras não assegura a comunicação.

O indivíduo é eminentemente um ser social, integrado, consciente ou inconscientemente nas articulações e atividades da sociedade. Partindo do pressuposto que redes sociais são a interligação do indivíduo ou organizações, com as relações de trabalho, amizades, informações e conhecimento que envolve o cotidiano das pessoas, essa rede pode, muitas vezes, não estar perceptível ao indivíduo, mas é inegável a sua influência no mundo corporativo. No caso aqui analisado, embora não reconhecida formalmente, pode-se perceber que as redes sociais sempre estiveram presentes.

Os bolivianos quando vieram para Corumbá com o intuito de fixarem residência, já haviam estado nessa cidade em algum momento. Alguns para visitar familiares que já estavam ali residindo; outros a passeio, já que a cidade se configurava como uma alternativa de lazer, favorecida pela linha ferroviária que operava entre esses países desde a década de 1950. Outra condição levantada foi o interesse comercial, na medida em que vinham para a compra de mercadorias nessa cidade ou ainda, como passagem para a realização dessa atividade em outros centros. Assim foi a maneira pela qual tomaram conhecimento do lugar e o elegeram como ideal para uma mudança, não só de residência, mas para melhoria de suas vidas.

Esse pensamento se aproxima da visão da geógrafa Claudia Pedone ao comentar as trajetórias dos migrantes desde sua origem e a importância da informação contida na rede:

Los contactos que se establecen mediante las trayectorias espaciales, los distintos anillos de las cadenas familiares, la información disponible en el lugar de llegada y los nuevos intereses que estos aspectos originan, se convierten en elementos tan importantes como los cálculos de bienestar económico a la hora de mantener en el tiempo el movimiento cíclico del proceso migratorio (PEDONE, 2003, p.105). 
Logo, a existência das redes sociais não apareceu explicitamente, mas implicitamente ficou evidenciada. Nessa ótica estão as relações interpessoais de um determinado grupo e que cada pessoa envolvida, independente de uma estrutura hierárquica, representa um elo nesse relacionamento. É tão natural que muitas vezes não é percebido pelos atores e agentes sociais envolvidos.

Foi possível observar então, dois principais vetores de acesso desses migrantes à cidade de Corumbá: a) a vontade própria, estimulada pelo interesse de melhoria das condições de vida; b) a influência de outros migrantes (conhecidos ou familiares) que já haviam se estabelecido nesta cidade e, que por sua vez, auxiliaram no sentido de apoiar os novos migrantes. Em ambas situações se observou o desejo latente de modificar sua condição de vida. Assim, aqueles que foram os pioneiros na vinda para essa cidade, após satisfazer minimamente seus anseios, tinham como passo seguinte a busca de seus familiares na terra natal.

Por outro lado, especialmente as mulheres entrevistadas indicaram a cooperação de brasileiros com relação à condição de empregá-los e orientá-los em suas atividades. Contudo, a facilidade de encontrar uma ocupação foi observada de forma geral, provavelmente pelo fato de que, indistintamente, aceitavam qualquer tipo de ofício mesmo que inicialmente não dominassem as tarefas, se empenhavam em aprendê-las.

Sobre essa "facilidade" e "orientação" em relação ao trabalho e seu real significado vale a pena alguns questionamentos: o fato desses migrantes se ocuparem de serviços gerais como camareiras, pedreiros, domésticas, não estaria mais vinculada à disponibilidade de mão-de-obra barata que eles representavam? Seria uma condição de aceitabilidade na sociedade local ou apenas a exploração de seu trabalho como uma mão de obra barata? Essa questão ganha força considerando que a maioria não desenvolveu essas funções de acordo com as normas trabalhistas, mas de maneira informal, geralmente condicionada pela dificuldade de documentação. Vale destacar que a menor remuneração relativa desse migrante não se constituía, imediatamente, num empecilho para o trabalho, já que comparativamente, a moeda brasileira é mais valorizada que a boliviana, proporcionando um maior poder aquisitivo.

De toda maneira, voluntária ou involuntariamente, as redes sociais se fizeram percebidas ao longo do processo migratório: seja nas relações de trabalho, relatadas 
como ponto principal que os mantiveram na cidade, seja nas relações pessoais, que contribuíram para que esses migrantes fossem motivados a vir e a ficar.

\section{As moradias dos bolivianos na cidade de Corumbá-MS}

A moradia, muito além do que ser destinada como teto, abrigo, está revestida de muitos significados. Na sua construção estão imbricados aspectos culturais, sociais, econômicos e físicos, cujas diferenças podem ser percebidas nas formas e estruturas nos mais diversos lugares.

Rapoport (1972, p.65) observa que:

La casa no es tan solo una estructura, sino una institución creada para un complexo grupo de fines. Porque la construcción de una casa es un fenómeno cultural, su forma e su organización están muy influidas por el "milieu" cultural al que pertenece. Desde hace mucho tiempo, la casa es, para el hombre primitivo, algo más que un techi $\mathrm{y}$, case desde el principio, la "función" era mucho más que un concepto físico o utilitario.

A moradia deve ser entendida como um complexo estrutural, funcional e afetivo que são componentes indispensáveis ao ser humano. Nas questões estruturais são pertinentes fatores internos e externos à residência: internamente, a forma como são organizadas as peças que constituem a casa, a disposição de seus móveis (colocados de acordo com as experiências e crenças de cada povo); externamente, o desenho, a paisagem e a moradia como um espaço de relacionamentos e da manifestação da cultura.

A caracterização das moradias será sempre reflexo material e imaterial, do poder econômico, estrutural e simbólico, resultados da ação do ser humano sobre a natureza. Santos (1997) explica que o cotidiano e suas transformações obedecem três ordens: da técnica, da forma jurídica e do simbólico. Para ele, a ordem técnica e a ordem da norma são tratadas como dados. Sendo assim, se pode deduzir que para a estruturação das moradias a ordem técnica seria a concepção arquitetônica norteadora dessa construção, ou seja, suas formas físicas e os materiais disponíveis utilizados para esse fim; a ordem jurídica seria as políticas habitacionais e as questões legais para edificação. Santos (1997, p.67) aponta que embora esses fatores sejam relevantes, "[...] a força da transformação e mudança, a surpresa e a recusa ao passado provem do agir simbólico, onde o que é força está na afetividade, nos modelos de significação e representação

Ateliê Geográfico Goiânia-GO v. 5,n. 3 dez/2011 p.127-149 Página


[...]”. Para ele a importância do lugar na formação da consciência advém do fato de que essas formas de agir são inseparáveis, ainda que, em cada circunstância, sua importância relativa não seja a mesma. Sobre este prima, buscou-se analisar as singularidades das residências dos bolivianos em Corumbá.

Nas observações da paisagem representada pelas moradias de Corumbá (Brasil) e Puerto Quijarro (Bolívia) se percebeu a existência de muitas semelhanças. Embora tenha sido frequente a afirmação de que as casas em Puerto Quijarro fossem construídas de forma diferente, com os cômodos no sentido do comprimento, em Corumbá essa característica também apareceu em algumas construções. A forma de organizar os cômodos "em departamentos", conforme sugeriu um dos entrevistados, em alusão às casas de Corumbá, também foi observada no lado boliviano e mencionado por migrante que possui residência em ambas as cidades. Apesar da diferença de acabamento (qualidade e investimento), se observa essa aproximação da paisagem residencial, com destaque para o quintal e varanda, bastante comuns nessas cidades (Figura 2).
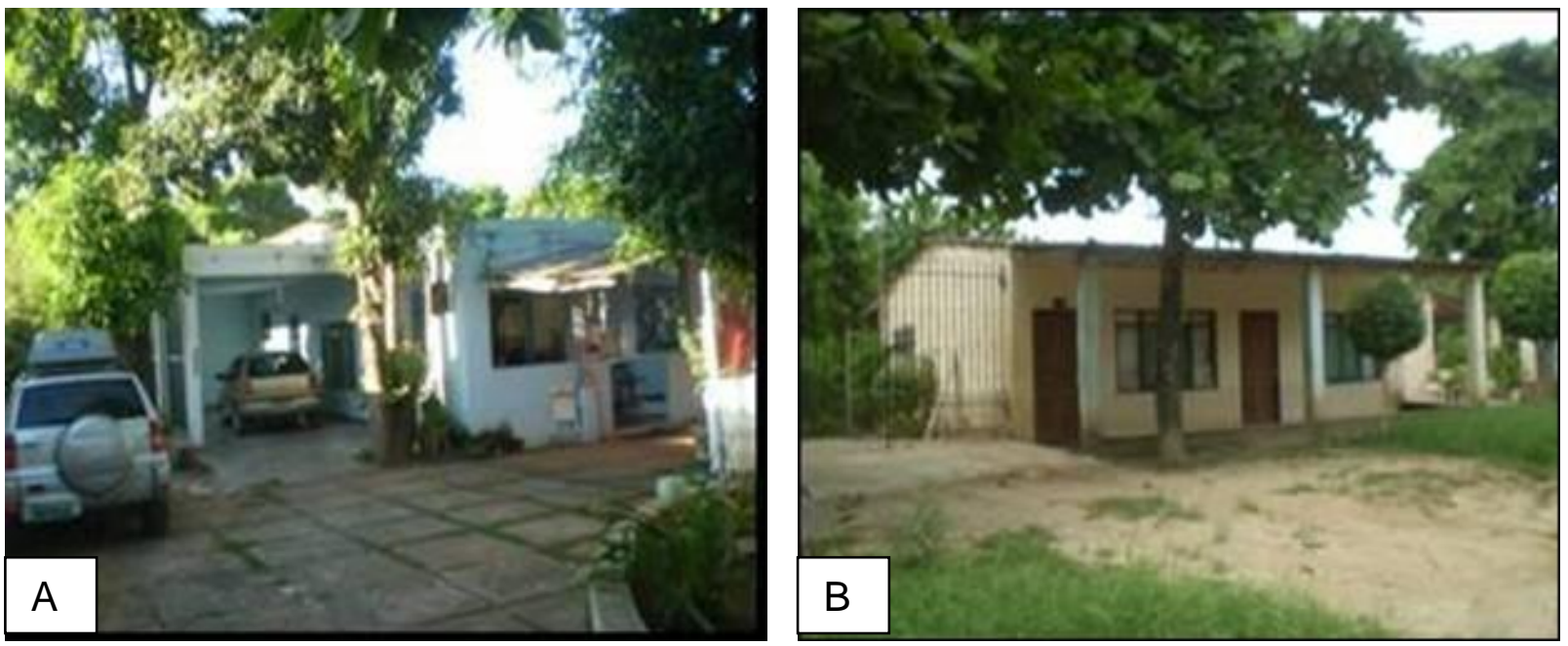

Figura 2. Varanda e quintal: singularidades residenciais de Corumbá, Brasil (A) e Puerto Quijarro, Bolívia (B). Autor: DIAS, R.T.R., 2010

A moradia funciona também como um espaço de relacionamento onde as pessoas se reúnem, tanto com a família, dividindo as experimentações cotidianas, quanto com as visitas com as quais convivem socialmente. Nota-se, com frequiência, edificações construídas de forma a destinar uma área especifica para essa finalidade (varandas e/ou quintais), onde diariamente desfrutam da companhia uns dos outros, da mesma forma como a sala de estar que também possui essa função. Nesse sentido, a

Ateliê Geográfico Goiânia-GO v. 5,n. 3 dez/2011 p.127-149 Página


parte frontal das residências também desempenha esse papel, como foi observado tanto em residências corumbaenses como em Puerto Quijarrro, onde as pessoas se reúnem em frente às casas, em espaços próprios ou mesmo nas calçadas (Figura 3), para momentos de descontração e relacionamentos com familiares e vizinhos.
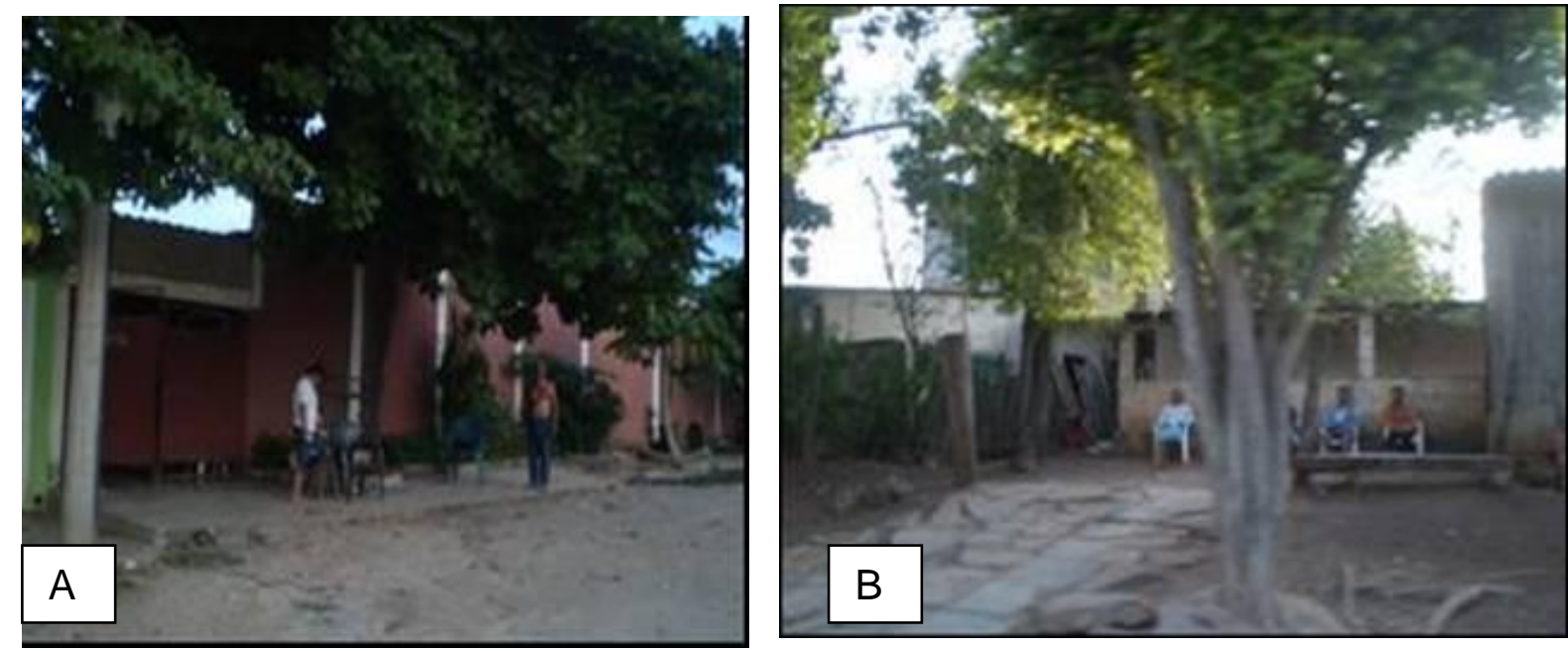

Figura 3. Reuniões em frente às residências - Corumbá (A) e Puerto Quijarro (B): hábitos comuns dos fronteiriços. Autor: DIAS, R.T.R., 2010

Esta prática tende a desaparecer com o crescimento e consequente medo da violência urbana. Ainda ocorre provavelmente por se tratar de cidades de pequeno a médio porte. Ratificando essa idéia, a fala de uma das entrevistadas chamou atenção quando pronunciou: "[...] antigamente a gente fazia as festas - natal e final de ano - no quintal, a casa ficava aberta a noite toda... a noite a gente ficava sentada aí fora, conversando com a família e os vizinhos [...] hoje eu tenho medo, por causa dos malandros... é perigoso...". Todavia, observar as pessoas em reuniões à porta de suas casas ainda não é uma cena incomum nas duas cidades, sobretudo durante o dia, mas a fala denota sinais de mudança.

A maioria dos bolivianos entrevistados afirmou serem proprietários de suas moradias e que houve determinação, empenho pessoal e familiar muito grande para a obtenção das mesmas. Não se constatou nenhum benefício institucional que os auxiliassem para o estabelecimento e construção de suas casas nesta cidade. Indagados sobre essa possibilidade, as respostas foram sempre similares: "tudo foi construído devagar, com muito esforço... minha mulher carregava carrinho com material para o terreno"; "a ajuda que tive foi que pude comprar o material em prestações"; "comprei a

Ateliê Geográfico Goiânia-GO v. $5, n .3$ dez/2011 p.127-149 Página


casa em parcelas... a pessoa que me vendeu foi boa, dividiu para mim em três vezes"; "consegui construir com muito trabalho".

Pelas declarações se percebe que os migrantes estavam integrados na sociedade local pelo trabalho. O fato de poderem comprar de forma parcelada demonstra a existência de comprovação de rendimento e residência fixa, dois fatores fundamentais para comprovar a formalidade de seu estabelecimento no Brasil. O salário e sua comprovação não só garante a possibilidade da compra a prazo, mas também transforma o boliviano num cidadão corumbaense e, portanto, brasileiro. A dupla nacionalidade dos bolivianos é uma das marcas dessa fronteira, cujas estratégias ainda carecem de mais investigações.

Essas declarações foram comprovadas, através de entrevista com o representante local do setor habitacional, que afirmou não ter conhecimento de nenhuma política habitacional para imigrantes e que as aquisições de suas moradias ocorrem de forma individual. Dessa maneira, não foram identificadas a existência de redes em nível político ou institucional, que estivessem diretamente voltadas para um acolhimento especial aos migrantes. Vale dizer que não se pretende, com isso, defender a implementação de políticas específicas para habitação do imigrante. Trata-se, tão somente, de uma constatação a partir da discussão de necessidades inerentes ao ser humano, independente de nacionalidades. Acredita-se que uma política habitacional deve garantir direitos iguais a todos os cidadãos que participam das atividades da sociedade local.

Em alusão ao tipo de moradia ideal e sobre a forma como estão organizadas suas residências atuais, se percebeu um sentimento de satisfação e orgulho pela concretização de um sonho e da conquista de um espaço "seu”. O significado da vitória está claramente manifestado em suas declarações e nas comparações com as moradias anteriores onde inicialmente habitavam: "aqui no terreno tinha duas peças que eu cobria com latas de óleo, aquelas redondas, que eu abria e usava para proteger a casa"; "a primeira casa era de tábua... construí depois com o dinheiro da indenização que recebi da firma". Essas características foram preponderantes nas falas de quase todos os entrevistados, evidenciando as dificuldades vividas e os obstáculos enfrentados e ultrapassados para obterem uma vida com melhores condições de conforto e dignidade, de acordo com suas próprias manifestações.

Ateliê Geográfico Goiânia-GO v. $5, n .3$ dez/2011 p.127-149 Página


Em termos comparativos sobre o lugar onde viviam e onde vivem a infraestrutura representa o maior diferencial, como pode ser percebido nas seguintes declarações: "as casas são iguais, aqui tudo é melhor, é limpo, a prefeitura exige que os terrenos sejam limpos, aqui tem mais higiene"; "lá as casas do centro são diferentes, no centro tem asfalto... agora que estão construindo casas mais ajeitadinhas... lá os cômodos passam de porta em porta, não é igual daqui, são separados"; "aqui o ambiente é melhor, tem mais limpeza".

A maioria não identificou diferenças na forma de organização das casas, mas foram citadas como marcantes as questões referentes à infra-estrutura da cidade, como a água encanada, energia, asfalto e manifestaram preocupação quanto aos cuidados de limpeza com o lugar. Em relação ao desenho das moradias se observou que as construções, quando comparadas (Figura 4), apresentam padrões externos muito similares, embora as disposições internas aparentem organização diferente, em algumas situações. Pelas entrevistas foi possível identificar que em Puerto Quijarro e em outras localidades bolivianas, as construções são feitas no sentido do "comprimento", ou seja, os cômodos são construídos lado a lado. Essa forma de construir foi modificada nas residências locais, onde os cômodos são construídos de forma agrupada, tendo, quase sempre, um corredor de interligação.

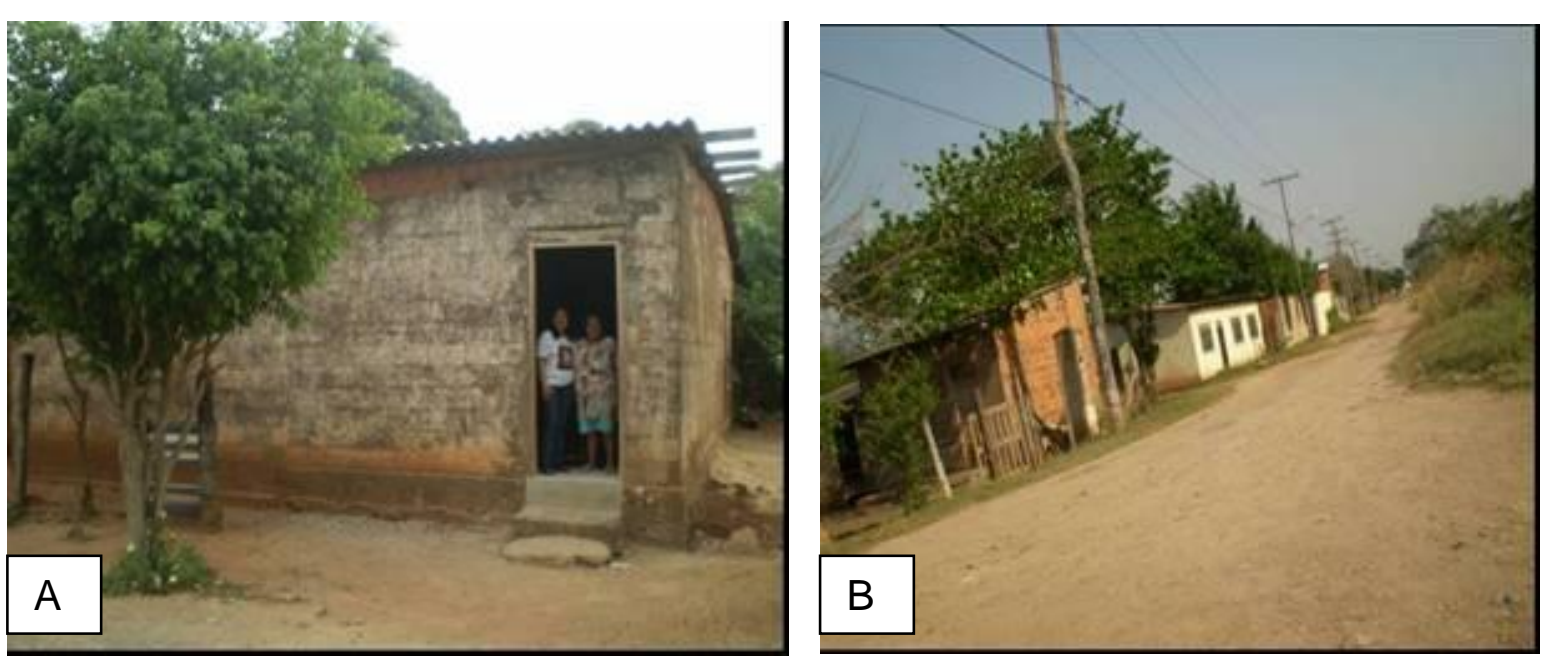

Figura 4. Semelhanças na paisagem cultural de Corumbá, Brasil (A) e Puerto Quijarro, Bolívia (B). Autor: DIAS, R.T.R., 2010.

Foi observado que grande parte das moradias localizadas em Corumbá permaneceu de forma inacabada, principalmente no que diz respeito ao reboco das

Ateliê Geográfico Goiânia-GO v. 5, n. 3 dez/2011 p.127-149 Página


paredes e outros cômodos da casa, justificados pela questão financeira dos residentes, que acabam realizando suas construções aos poucos. Essas características também foram notadas em Puerto Quijarro. Entretanto, se descobriu que essa prática é comum naquela cidade, funcionando como uma estratégia para se esquivar do pagamento de impostos, já que naquele município os impostos são exigidos apenas para construções concluídas. Portanto, nesse caso não seriam passíveis de comparações em termos de estratégias, pois em Corumbá a condição de conclusão da casa não é prerrogativa para cobrança de impostos.

De todo modo, a moradia está diretamente relacionada como um dos desejos primordiais do ser humano, não apenas com o sentido de habitação, mas pelo significado nela embutido. A casa é o porto seguro de todo ser humano, o lugar onde se sente protegido e onde ele pode manifestar toda sua individualidade e o seu poder. É nesse espaço que se concretiza o relacionamento com seus entes queridos. A possibilidade de adquirir a moradia própria é um dos maiores sonhos. Isso pôde ser ratificado nas falas dos entrevistados, que manifestaram a tranqüilidade e a alegria de poderem ter construído suas moradias e a felicidade que isso representou em suas vidas: "aqui é um lugar abençoado e sou feliz, porque construí minha casa e minha família aqui"; "não sou mais feliz aqui só por causa da saúde, mas tenho minha casa e família"; "tenho o que preciso para viver bem [...] minha casa, família, bons vizinhos"; "aqui consegui trabalho e pude construir a minha casa onde vivo com minha família", "aqui é um lugar bom, sossegado".

Com relação ao tipo de moradia dos entrevistados, de padrões modestos, a maioria declarou ser proprietário dos imóveis, construídos a partir da aquisição de um terreno. Inicialmente residiam em pequenos cômodos e as ampliações foram feitas na medida em que adquiriam condições financeiras para tal. Boa parte dessas residências ainda permanece sem acabamentos, como a finalização das paredes, pintura, portas, etc. No imaginário de muitos deles está muito presente a idealização de projetos de edificação de novos cômodos, de ampliação da casa. Esse fato está diretamente vinculado ao poder aquisitivo desses indivíduos.

Outra característica observada nas moradias desses migrantes foi a forma e o local da construção das mesmas. Quase sempre em terrenos amplos e com a seguinte distribuição dos cômodos: dois a quatro quartos, sala, cozinha, banheiro, área de serviço

Ateliê Geográfico Goiânia-GO v. 5,n. 3 dez/2011 p.127-149 Página


e quintal. Uma observação muito freqüente foi a existência de uma outra casa, geralmente menor (Figura 5), utilizada como moradia dos filhos. Neste ponto foi ressaltado por alguns, a importância da proximidade e convivência familiar, sendo não rara a ocorrência de filhos adultos residindo na casa dos pais.

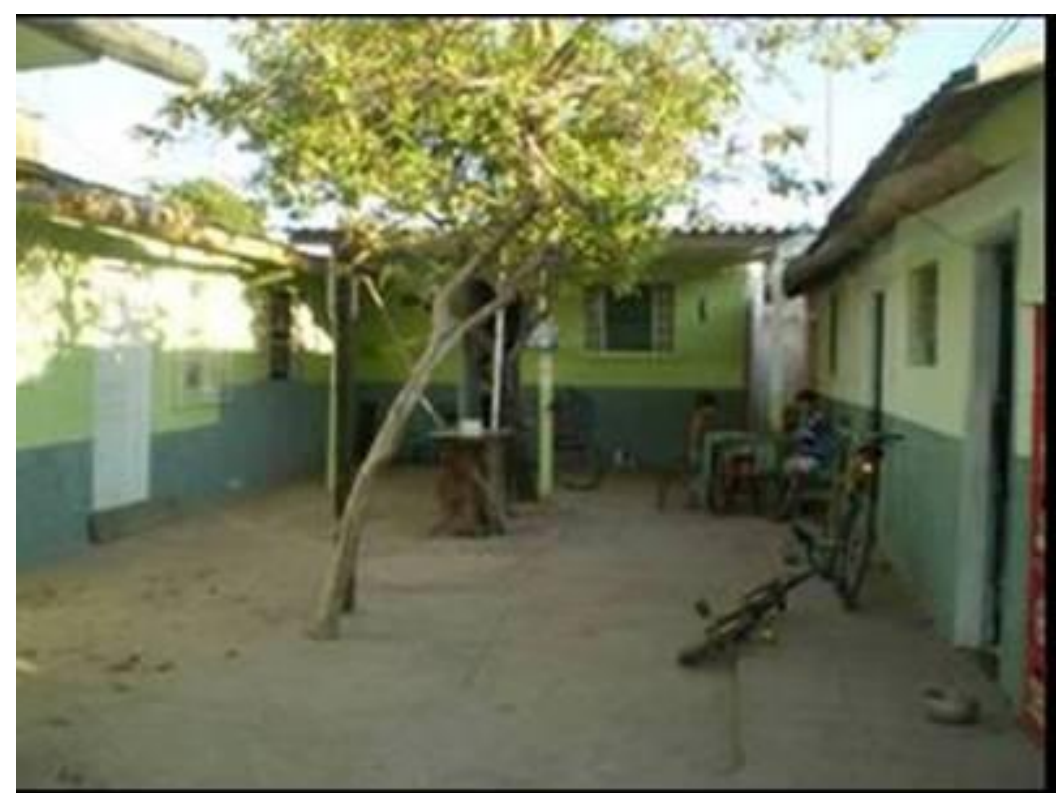

Figura 5. Organização espacial das moradias dos bolivianos, na cidade de Corumbá-MS, Brasil.

Autor: DIAS, R.T.R., 2010.

A sala e a varanda foram apontadas como os lugares mais importantes da casa, pela possibilidade de integração e lazer com a família, sendo muitas vezes o lugar onde se realizam quase todas as atividades familiares (Figura 6). Além disso, a sala se destaca pela existência do televisor, onde as pessoas passam grande parte do tempo, como uma forma de entretenimento, já que se trata de uma forma de lazer predominantemente aludida pelo grupo de entrevistados. 


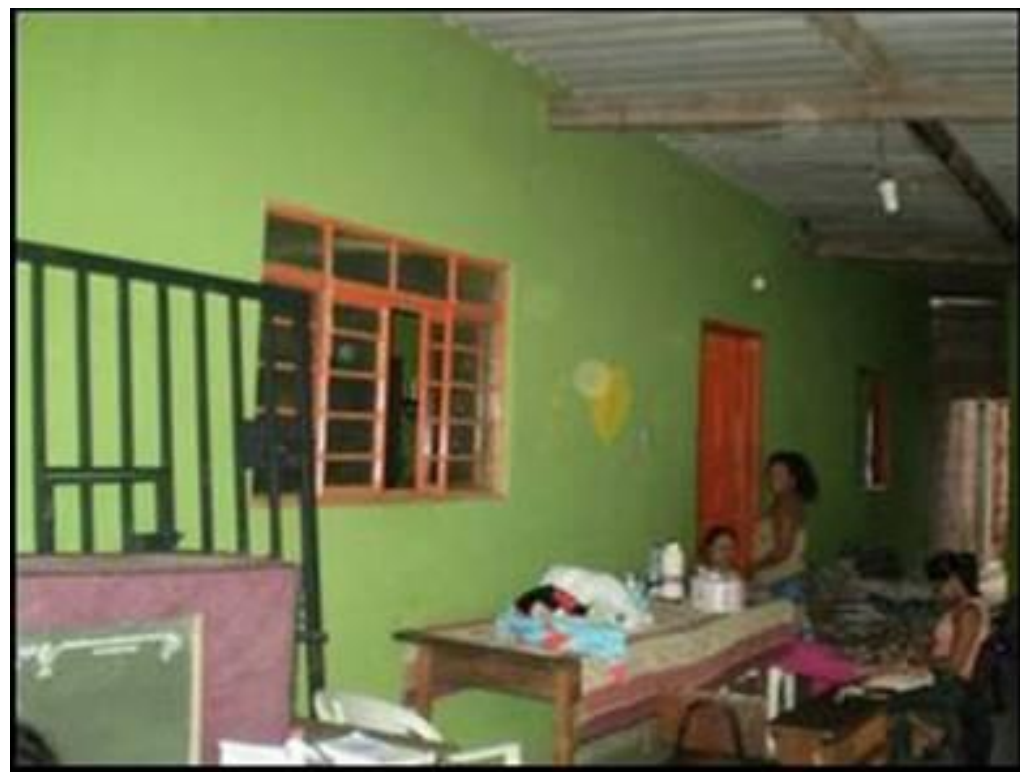

Figura 6. Varanda: um local de encontro nas moradias dos bolivianos, na cidade de Corumbá-MS, Brasil. Autor: DIAS, R.T.R., 2009.

Essa predominância de convívio das pessoas na sala e na varanda ou quintal apresentam similaridades com as residências dos corumbaenses, principalmente nos bairros mais afastados do centro. Provavelmente a sala tenha sido eleita por ser um dos cômodos maiores nas residências, e onde comumente as visitas são recebidas. No que diz respeito à varanda ou quintal, também foi indicado como um espaço de convivência, possivelmente por se constituir de uma área ampla e aberta, que permite a circulação mais livre das pessoas, bem como um refúgio do calor intenso que ocorre dentro das residências, já que a temperatura cotidiana da cidade é bem elevada (quase sempre superior a $35^{\circ} \mathrm{C}$ ) na maior parte do ano. A varanda, e por extensão o quintal, também é o local das pequenas festas em família, como aniversários, comemorações natalinas e de final de ano.

Uma forte singularidade entre as cidades de Corumbá e Puerto Quijarro é dada pela visão que se tem nas ruas de ambas as cidades (Figura 7): casas com pequenas plantações que se misturam com as construções, ruas bastante arborizadas. Tanto que em determinadas fotografias essas ruas se confundem pela semelhança, seja nas disposições das casas, seja pela vegetação ou pela presença de pessoas reunidas nas portas de suas casas. 

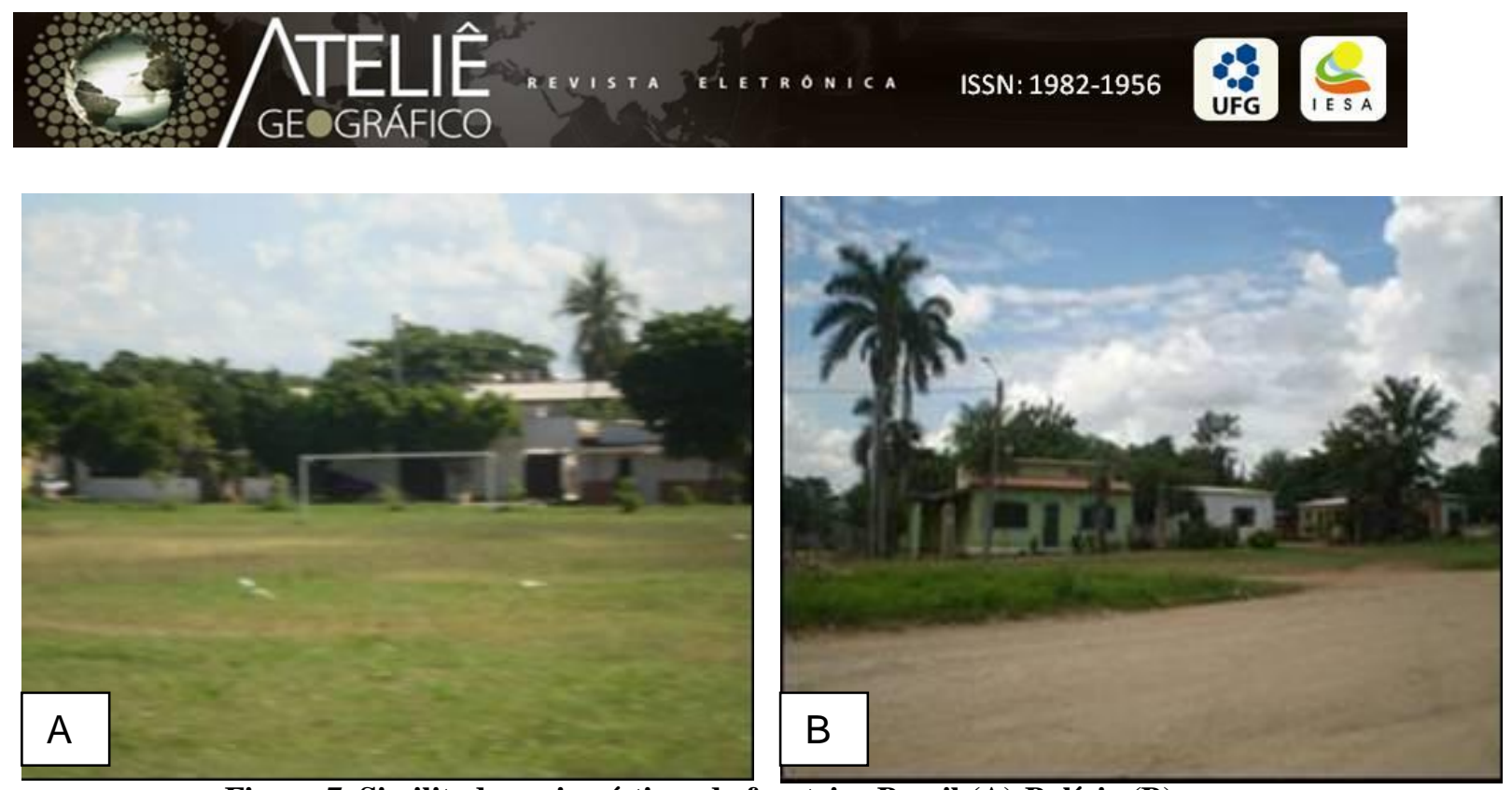

Figura 7. Similitudes paisagísticas da fronteira Brasil (A)-Bolívia (B).

Autor: DIAS, R.T.R., 2010.

Outra característica marcante é a forma das construções que servem também para as atividades comerciais. As casas são planejadas deixando uma porta maior com acesso a um cômodo que posteriormente será utilizado com finalidade comercial. Normalmente se localiza ao lado da sala de estar, sendo interligada com todo o ambiente construído (Figura 8). Assim que possível financeiramente já começam a fazer funcionar a atividade comercial na casa. Os recursos conseguidos com a atividade ajudam na conclusão da obra e apóiam a composição da renda familiar.
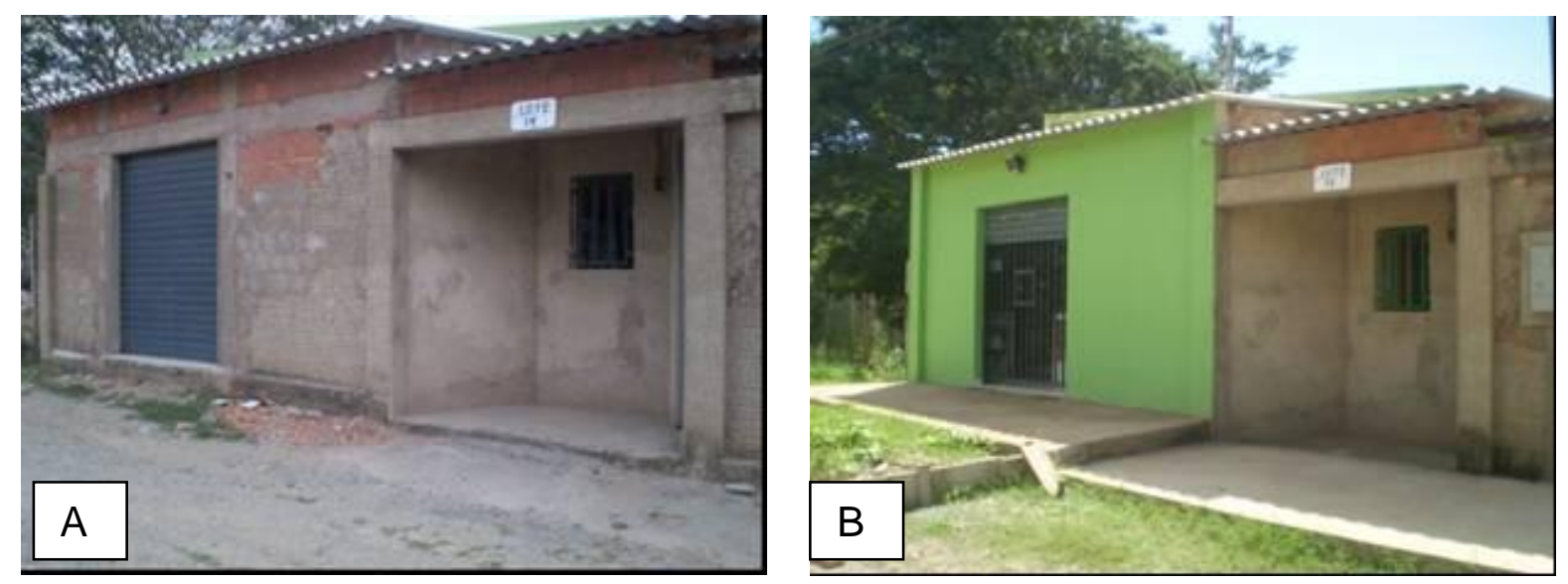

Figura 8. Moradia localizada em Corumbá, Brasil, antes (A) e após (B) a sua conclusão, com espaço para a realização de pequeno comércio. Autor: DIAS, R.T.R., 2009 (A) e 2010 (B).

Essa forma de associar moradia e comércio é muito praticada em Corumbá, especialmente fora do centro da cidade. Cabe ressaltar que, em muitos casos, a entrada do cliente no estabelecimento é vedada, sendo o atendimento realizado por uma

Ateliê Geográfico Goiânia-GO v. 5, n. 3 dez/2011 p.127-149 Página




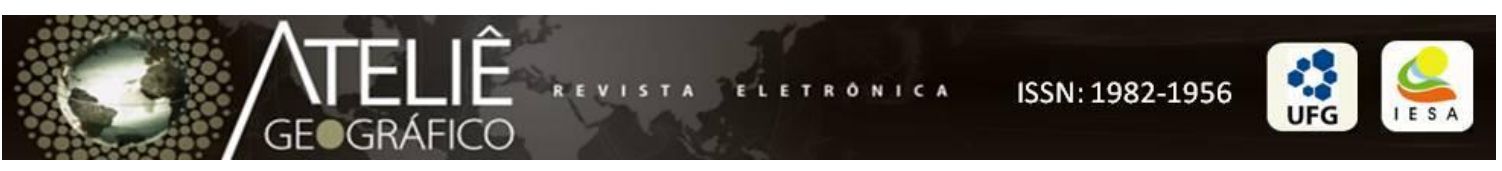

portinhola estrategicamente colocado na grade de proteção da porta. A porta fica aberta, mas a grade permanece fechada e os clientes fazem o pedido através da mesma. Trata-se de uma estratégia contra possíveis assaltos. Enfim, os arranjos espaciais, nessa fronteira, ganharam as características do território, misturados com as heranças trazidas pelos migrantes.

\section{Considerações finais}

As territorialidades são produzidas no território e são, ao mesmo tempo, (re)produtoras do mesmo. São resultados das intencionalidades de indivíduos, grupos, empresas ou instituições para sobrevivência, criação e/ou uso de infraestruturas, acúmulo de riquezas ou qualquer outra motivação. Os migrantes bolivianos ao chegarem no Brasil encontraram um território com características muito diferentes dos seus locais de origem. Diante disso, produziram novas territorialidades em acordo com o contexto e as possibilidades vislumbradas. Isso não significa que se despiram completamente dos conhecimentos anteriores, mas que houve um re(arranjo) dos mesmos para desenvolverem estratégias de permanência na cidade de Corumbá.

Através das narrativas, das emoções manifestadas durante as entrevistas e das observações do cotidiano e da paisagem fronteiriça, se pôde perceber que os migrantes bolivianos idealizaram na cidade de Corumbá a realização de um sonho. Corumbá passou a ser sinônimo da concretização das perspectivas de melhor qualidade de vida, numa caminhada sem retorno para terra natal. A razão fundamental para essa migração foi a busca por oportunidades de emprego, independente da qualidade, e moradia digna. Sem muitas exigências para o tipo de trabalho, esses migrantes satisfizeram plenamente seus desejos na nova localidade.

As territorialidades dos migrantes bolivianos impulsionaram novas formas no território, observadas na construção de suas moradias com singular arranjo para uso comercial. Contudo, essas materialidades, quando vistas no contexto geral da paisagem urbana fronteiriça não são facilmente notadas, pois são arranjadas em terrenos e ruas similarmente arborizadas.

Finalmente, entendemos que uma das estratégias adotadas pelos bolivianos em Corumbá foi a de permanecer "invisíveis" da sua condição de migrante, até que a língua

Ateliê Geográfico Goiânia-GO v. 5,n. 3 dez/2011 p.127-149 Página


não fosse um constrangimento e até que estivessem plenamente integrados ao novo meio. Entretanto, essa invisibilidade tem que ser vista de forma relativa, pois os mesmos interagiram com o ambiente, com as pessoas, na busca de suas necessidades e desejos de mudança da condição de vida. Esses indivíduos demonstraram extraordinária capacidade em lidar com o "novo", em assimilar novas práticas, em estabelecer uma imediata reterritorialização, ajudando a impulsionar a dinâmica de (re)construção do território fronteiriço.

\section{Referências}

BAENINGER, Rosana; SOUCHAUD, Silvain. Vínculos entre a migração internacional e a migração interna: o caso dos bolivianos no Brasil. In: Taller Nacional sobre "Migración interna y desarrollo en Brasil: diagnóstico, perspectivas y políticas". Brasília: CELADE, 2007.

CASTROGIOVANNI, Antonio Carlos; GASTAL, Susana. Fronteiras e turismo: tensionando conceitos. In. IV SEMINTUR - Seminário de Pesquisa em Turismo do MERCOSUL; III Seminário de Associação Nacional de Pesquisa e Pós Graduação em Turismo. Caxias do Sul - 7 e 8 de julho de 2006, p.1-15.

COSTA, Edgar Aparecido da. Ordenamento territorial em áreas de fronteira. In: COSTA, E.A; OLIVEIRA, M.A.M. Seminário de estudos fronteiriços. Campo Grande: Editora UFMS, 2009, p. 61-78.

DELEUZE, Gilles; GUATTARI, Felix. Mil platôs: capitalismo e esquizofrenia. Vol. 5. Rio de Janeiro: Editora 34, 1997.

GOLGHER, André Braz. Fundamentos da migração. Belo Horizonte: UFMG/Cedeplar, 2004.

HAESBAERT, Rogério. Território e Multiterritorialidade: um debate. GEOgraphia (UFF), v. 17, p. 19-45, 2008.

O mito da desterritorialização: do "fim dos territórios" à multiterritorialidade.

1. ed. Rio de Janeiro: Bertrand Brasil, 2004. v. 1. 400 p.

Da desterritorialização à multiterritorialidade. Boletim Gaúcho de Geografia, Porto Alegre, v. 29, n. 1, p. 11-24, 2003.

A multiterritorialidade do mundo e o exemplo da Al Qaeda. Terra Livre, São Paulo, v. 12, p. 34-65, 2002.

NOGUEIRA, Ricardo José Batista. Fronteira: Espaço de referência identitária? Revista Ateliê Geográfico, Goiânia, v. 1, n. 2, dez/2007, p.27-41.

PEDONE, Claudia. "Tu siempre jalas a los tuyos": cadenas y redes migratórias de las familias ecutorianas hacia España. Tese de Doutorado. Barcelona: Universidade Autônoma de Barcelona, 2003.

RAFFESTIN, Claude. Por uma geografia do poder. São Paulo: Ática, 1993.

Ateliê Geográfico Goiânia-GO v. $5, n .3$ dez/2011 p.127-149 Página


RAPOPORT, Amos. Vivienda y cultura. (Traduação: Conchita Diez de Espada). Barcelona: Gustavo Gill, 1972.

SANTOS, Milton. A natureza do espaço: técnica e tempo, razão e emoção. 2.ed. São Paulo: Ed. Hucitec, 1997.

SAQUET, Marcos Aurélio. Abordagens e concepções do território. São Paulo: Expressão Popular, 2007.

Recebido para publicação em fevereiro de 2011.

Aprovado para publicação em junho de 2011. 